\title{
Bulk Amorphous Formation and Magnetic Properties of Nd-Fe-Co-Al Alloys by the New Gas Jet Flow Type Levitating Process
}

\author{
Shuji Azumo*, Seishi Utsuno* and Katsuhisa Nagayama \\ Department of Materials Science, Faculty of Engineering, Shibaura Institute of Technology, Tokyo 135-8548, Japan
}

\begin{abstract}
The amorphous formation ability and the magnetic properties of $\mathrm{Nd}_{60} \mathrm{Fe}_{30-x} \mathrm{Co}_{x} \mathrm{Al}_{10}(x=10,15,20$ or 30$)$ alloys in the containerless process were studied by the new gas jet flow type levitating process. The gas jet flow type levitating process enables solidification without any container wall by the inert gas jet. The samples were solidified at the cooling rate of around $100 \mathrm{~K} / \mathrm{s}$. Then, the undercooling of samples exhibits high values $(\Delta T=60-150 \mathrm{~K})$. From X-ray diffraction measurements, the $\mathrm{Nd}_{60} \mathrm{Fe}_{30-x} \mathrm{Co}_{x} \mathrm{Al}_{10}$ samples exhibit a typical broad diffraction pattern for an amorphous structure. The DTA curves of $x=10,15$ and 20 showed an exothermic peak due to the crystallization. That is, it was revealed that the $\mathrm{Nd}_{60} \mathrm{Fe}_{30-x} \mathrm{Co}_{x} \mathrm{Al}_{10}$ samples formed bulk amorphous. Also, the coercivity is 1.6, 3.3 and $3.6 \mathrm{kOe}$ for the $\mathrm{Nd}_{60} \mathrm{Fe}_{20} \mathrm{Co}_{10} \mathrm{Al}_{10}$, $\mathrm{Nd}_{60} \mathrm{Fe}_{15} \mathrm{Co}_{15} \mathrm{Al}_{10}$ and $\mathrm{Nd}_{60} \mathrm{Fe}_{10} \mathrm{Co}_{20} \mathrm{Al}_{10}$, respectively. From the thermomagnetic curves, the Curie temperature is determined to be 463 , 482 and $482 \mathrm{~K}$ for the $\mathrm{Nd}_{60} \mathrm{Fe}_{20} \mathrm{Co}_{10} \mathrm{Al}_{10}, \mathrm{Nd}_{60} \mathrm{Fe}_{15} \mathrm{Co}_{15} \mathrm{Al}_{10}$ and $\mathrm{Nd}_{60} \mathrm{Fe}_{10} \mathrm{Co}_{20} \mathrm{Al}_{10}$, respectively. In the $\mathrm{M}$ - $\mathrm{H}$ loops and the thermomagnetic curves, this difference between $x=10$ and $x=15,20$ may depend on the microstructure. [doi:10.2320/matertrans.47.1568]
\end{abstract}

(Received October 25, 2005; Accepted April 13, 2006; Published June 15, 2006)

Keywords: containerless process, $\mathrm{Nd}_{60} \mathrm{Fe}_{30-x} \mathrm{Co}_{x} \mathrm{Al} l_{10}$, bulk amorphous, metastable phase, high coercivity

\section{Introduction}

The containerless process is one of the methods for high undercooling appearance and is expected to enable the undercooling-dependent formation of bulk amorphous or metastable phase. By using the containerless process such as the electrostatic levitation and the drop tube, the glass forming ability, the metastable phase formation and high undercooling have been reported. ${ }^{1,2)}$ We have reported about the solidification behavior, the local structure, the hard magnetic property and the effect of micro-gravity by the containerless process, ${ }^{3,4)}$ especially $\mathrm{Nd}-\mathrm{Fe}$ alloys. ${ }^{5,6)}$ The metastable phase with high coercitivity features in $\mathrm{Nd}-\mathrm{Fe}$ alloys, and high coercitivity appearance may be caused by the random magnetic coupling between $\mathrm{Nd}$ atoms and $\mathrm{Fe}$ atoms. The levitated samples show a higher coercitivity, and we have proposed the validity of containerless process. ${ }^{7)}$ Also, we have reported about the high coercitivity phase formation and the local structure of $\mathrm{Nd}-\mathrm{Fe}-\mathrm{Al}$ alloy. ${ }^{8)} \mathrm{In}$ this alloy, $\mathrm{Al}$ is added to the Nd-Fe alloy to increase the metastable phase formation ability. The gas jet flow type levitating process is different from the existing electromagnetic levitating process $^{5)}$ and can achieve the containerless process by flowing the inert gas jet for levitating and cooling and using the electromagnetic power only to heat the samples.

In this study, by the gas jet levitating method, we examined the Nd-Fe-Co-Al alloys. So as to improve the magnetic properties, $\mathrm{Co}$, which has higher magnetic anisotropy than that of Fe metal, is added to the Nd-Fe-Al alloy. The Nd-FeCo-Al alloys have also the high bulk glass-forming ability. Therefore, high undercooling, the formation of bulk amorphous alloys, the local structure and the magnetic properties of $\mathrm{Nd}-\mathrm{Fe}-\mathrm{Co}-\mathrm{Al}$ alloys were studied in detail.

\section{Experimental}

The ingots of $\mathrm{Nd}_{60} \mathrm{Fe}_{30-x} \mathrm{Co}_{x} \mathrm{Al}_{10}(x=10,15,20$ or 30$)$

*Graduate Student, Shibaura Institute of Technology

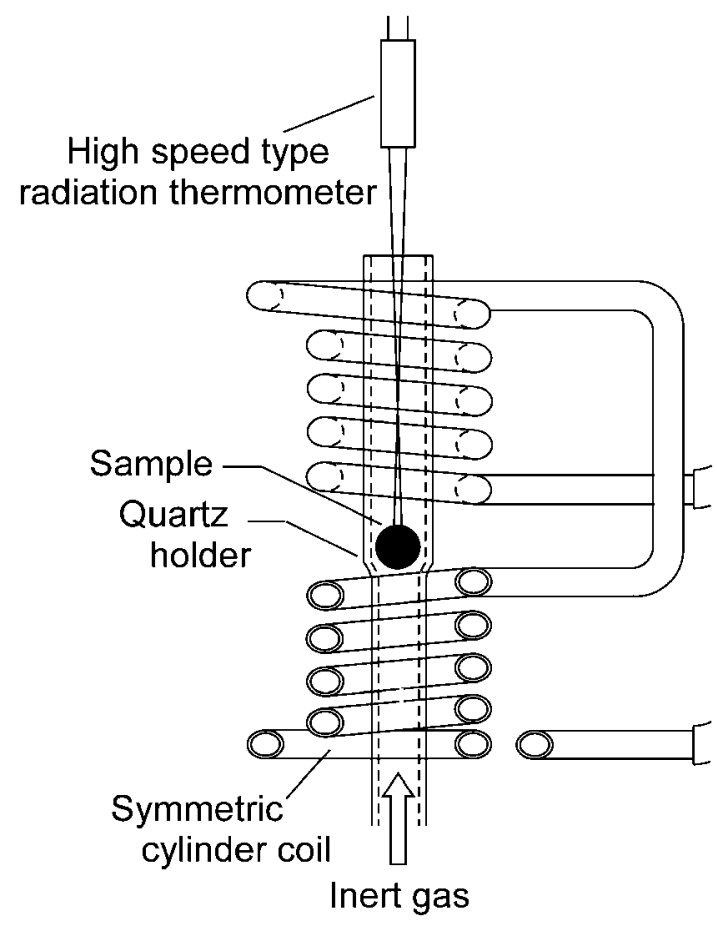

Fig. 1 Schematic diagram of gas jet flow type electro-magnetic levitating solidification system.

alloys (alloy composition are given in nominal atomic percents) were prepared by arc melting the mixtures of pure $\mathrm{Nd}(99.9$ mass \%), $\mathrm{Fe}(99.99$ mass\%), $\mathrm{Co}(99.9$ mass\%) and $\mathrm{Al}(99.99$ mass\%) in $\mathrm{Ar}$ gas atmosphere. The spheres with $6 \mathrm{~mm}$ in diameter were prepared from these ingots to use as samples for levitation.

Figure 1 shows the schematic diagram of gas jet flow type electromagnetic levitation system, which enables the containerless solidification process by using the inert gas jet flow. We made the cylinder type induction coil consisting of the midair copper pipe with $6 \mathrm{~mm}$ in diameter, which differs from the conventional coil ${ }^{5)}$ reported by us. The levitated melt was cooled by only gas jet flow when the electro- 


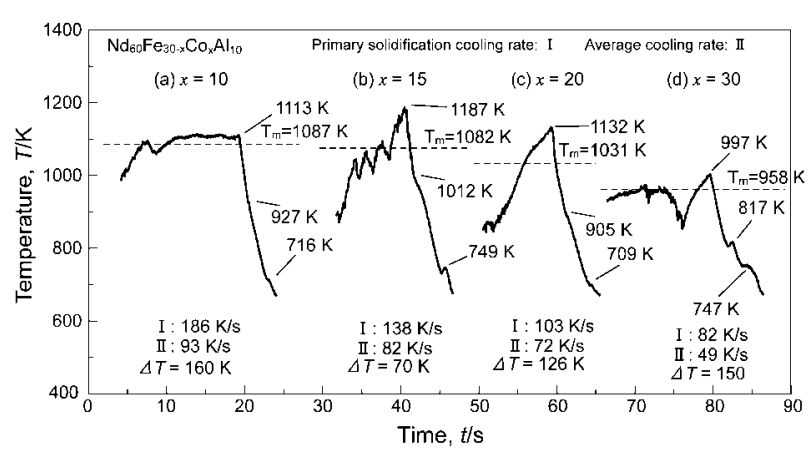

Fig. 2 Cooling curves of $\mathrm{Nd}_{60} \mathrm{Fe}_{30-x} \mathrm{Co}_{x} \mathrm{Al}_{10}$ samples $(x=10,15,20$ and 30) which solidified at the cooling rate of around $100 \mathrm{~K} / \mathrm{s}$ without container. Undercooling $\Delta T$ was defined as the melting temperature minus the nucleation temperature of primary crystal. $T_{m}$ indicates the melting temperature. Temperatures in cooling curves indicate the maximum heating temperature, the nucleation temperature of primary crystal and the eutectic reaction temperature.

magnetic power was shut down. However, the levitated sample was kept in stable condition by only gas jet flow.

The furnace chamber was evacuated to $10^{-3} \mathrm{~Pa}$ by turbo molecular pump and then filled with Ar gas. The spherical sample with $6 \mathrm{~mm}$ in diameter was levitated under gas jet flow in quartz holder with $8 \mathrm{~mm}$ in diameter and $50 \mathrm{~mm}$ in length and then the levitated sample was melted by electromagnetic levitation with $10 \mathrm{~kW}$ high frequency power supply. The temperature of the levitated sample was measured by high speed type two-color pyrometer with $\mathrm{Si}$ and InGaAs photodiode as detecting component to examine the solidification behavior with undercooling for Nd-based alloys. The levitated sample solidified by He gas jet.

The structure of the solidified samples was examined by Xray diffractometer (XRD) using $\mathrm{CuK} \alpha$ radiation at room temperature. The differential thermal analysis (DTA) of samples was carried out to identify an amorphous phase and determine the crystallization temperature, $T_{x}$, and the glass transition temperature, $T_{g}$, with a heating rate of $0.33 \mathrm{~K} / \mathrm{s}$. The magnetic properties of the solidified sample were measured by the vibrating sample magnetometer (VSM) at room temperature. Temperature dependence of magnetization of $\mathrm{Nd}_{60} \mathrm{Fe}_{30-x} \mathrm{Co}_{x} \mathrm{Al}_{10}$ samples ( $x=10,15$ and 20) was measured at a maximum applied field of 500 Oe. The Curie temperature was defined as the point of intersection between the linearly extrapolated curves of ferromagnetic and paramagnetic temperature region in this study. The microstructure observation was performed by a scanning electron microscopy equipped with energy dispersion spectroscopy (SEM-EDS).

\section{Results and Discussions}

\subsection{Solidification process with undercooling and bulk amorphous formation}

Figure 2 shows the cooling curves for the solidified $\mathrm{Nd}_{60} \mathrm{Fe}_{30-x} \mathrm{Co}_{x} \mathrm{Al}_{10}(x=10,15,20$ and 30$)$ samples in the containerless state. The samples were solidified by He gas jet flow with $10 \mathrm{~L} / \mathrm{min}$ constant flow rate by shutting down high frequency power. Also, a levitated sample was kept from the levitating start to the termination of solidification in stable

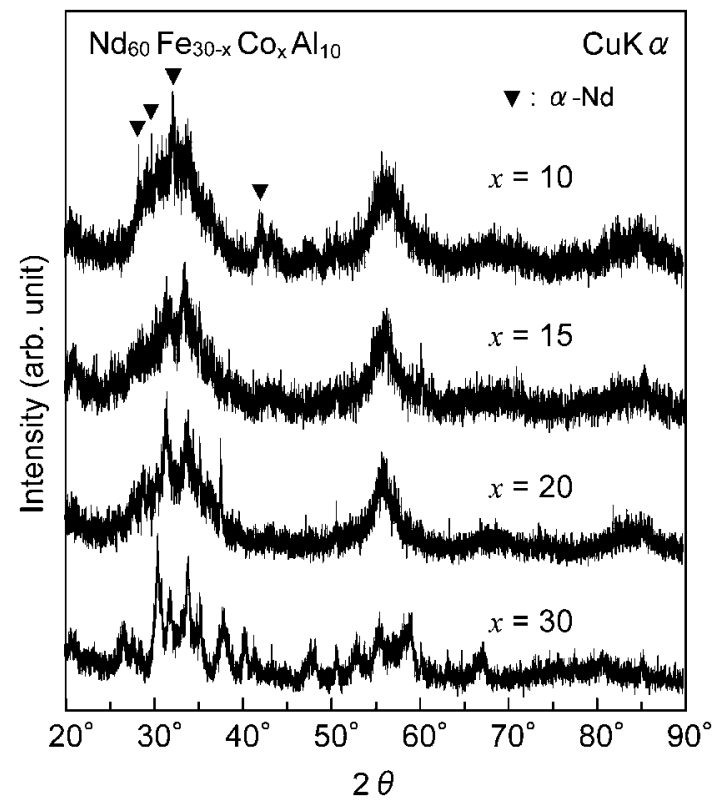

Fig. 3 XRD patterns of $\mathrm{Nd}_{60} \mathrm{Fe}_{30-x} \mathrm{Co}_{x} \mathrm{Al}_{10}$ samples $(x=10,15,20$ and 30) which solidified at the cooling rate of around $100 \mathrm{~K} / \mathrm{s}$ in the containerless state.

condition. In all cooling curves of Fig. 2, the samples (a), (b), (c) and (d) were heated up to $1113,1187,1132$ and $997 \mathrm{~K}$, respectively. The nucleation temperatures of primary crystal of the samples (a), (b), (c) and (d) are 927, 1012, 905 and $817 \mathrm{~K}$, followed by the eutectic reaction at 716, 749, 709 and $747 \mathrm{~K}$, respectively. The average of the primary solidification cooling rate and the average cooling rate (cooling rate from cooling start to the detection limit for pyrometer) are approximately $100 \mathrm{~K} / \mathrm{s}$ and $60 \mathrm{~K} / \mathrm{s}$, respectively. Then, the undercooling $\Delta T$, defined as the melting temperature minus the nucleation temperature of primary crystal, showed high values as $70-160 \mathrm{~K}$. The ratio of the undercooing $\Delta T$ and the melting temperature $T_{m}, \Delta T / T_{m}$, is $0.06-0.15$. Figure 3 shows the XRD patterns of the samples corresponding to Fig. 2. As can be seen, the XRD pattern for $\mathrm{Nd}_{60} \mathrm{Fe}_{20^{-}}$ $\mathrm{Co}_{10} \mathrm{Al}_{10}$ sample reveals the characteristic broad diffraction peaks typical of an amorphous structure. But then $\alpha$-Nd peaks were detected in XRD pattern, too. The XRD patterns for $\mathrm{Nd}_{60} \mathrm{Fe}_{15} \mathrm{Co}_{15} \mathrm{Al}_{10}$ and $\mathrm{Nd}_{60} \mathrm{Fe}_{10} \mathrm{Co}_{20} \mathrm{Al}_{10}$ samples consist of an amorphous phase and partial crystalline phases. The structure of these two samples is just about equal. In XRD patterns, $\alpha$-Nd peaks, however, were not detected in XRD patterns unlike the $\mathrm{Nd}_{60} \mathrm{Fe}_{20} \mathrm{Co}_{10} \mathrm{Al}_{10}$ sample. Though the undercooling of $\mathrm{Nd}_{60} \mathrm{Co}_{30} \mathrm{Al}_{10}$ in the cooling curves is the second largest value, the crystalline phases are predominant in the XRD pattern. Figure 4 shows the DTA curves of $\mathrm{Nd}_{60} \mathrm{Fe}_{30-x} \mathrm{Co}_{x} \mathrm{Al}_{10}(x=10,15$ and 20$)$ samples obtained during continuous heating with $0.33 \mathrm{~K} / \mathrm{s}$. Two exothermic peaks were observed in all DTA curves. However, the glass transition temperature wasn't observed in the DTA curves. The low temperature exothermic event has broad peak in all DTA curves, and the onset temperature of exothermic peak is $610 \mathrm{~K}, 624 \mathrm{~K}$ and $634 \mathrm{~K}$ for the sample (a), (b) and (c), respectively. The exothermic peak in the higher temperature region is $770 \mathrm{~K}, 788 \mathrm{~K}$ and $777 \mathrm{~K}$ for $x=10,15$ and 20 , 


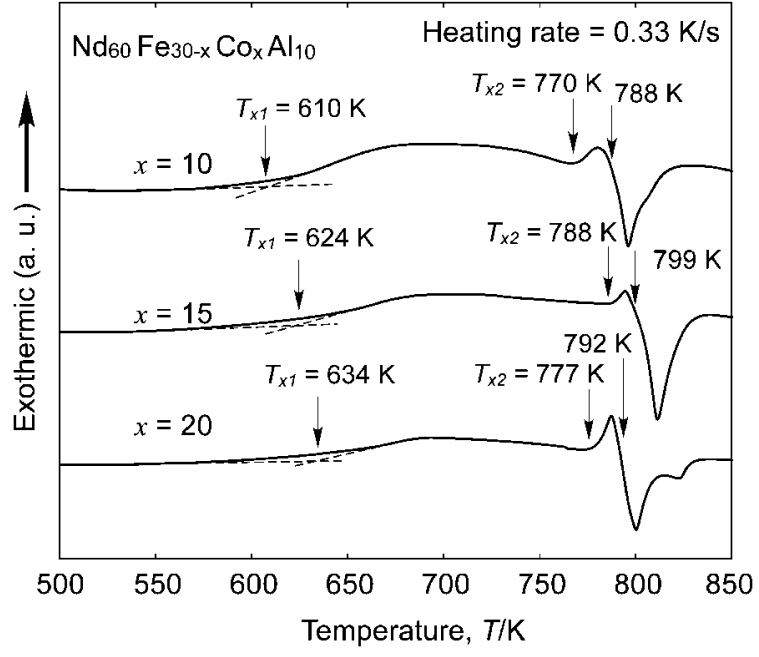

Fig. 4 DTA curves of $\mathrm{Nd}_{60} \mathrm{Fe}_{30-x} \mathrm{Co}_{x} \mathrm{Al}_{10}$ samples $(x=10,15$ and 20$)$ which solidified at the cooling rate of around $100 \mathrm{~K} / \mathrm{s}$ in the containerless state. $T_{x 1}$ and $T_{x 2}$ indicate the crystallization temperature. The eutectic temperature of $x=10, x=15$ and $x=20$ sample is $788 \mathrm{~K}, 799 \mathrm{~K}$ and $792 \mathrm{~K}$, respectively.

respectively. These exothermic peaks correspond to the massive crystallization of amorphous phase. Also, in the immediate aftermath of the exothermic peak at $770 \mathrm{~K}, 788 \mathrm{~K}$ and $777 \mathrm{~K}$ for $x=10,15$ and 20, respectively, the endothermic heat flow event is observed. These behaviors, the endothermic peak in the immediate aftermath of the exothermic peak, agree well with previously published results on Nd-based amorphous alloys. ${ }^{9)}$ In these published results, the broad exothermic peak was attributed to an early crystallization or growth of crystalline phases. In this study, in order to elucidate the broad exothermic peak, the DTA measurement was carried out repeatedly. All the exothermic peaks are irreversible reaction, as each of them disappears in a second heating run. This indicates that $\mathrm{Nd}_{60} \mathrm{Fe}_{30-x} \mathrm{Co}_{x} \mathrm{Al}_{10}$ $(x=10,15$ and 20) samples formed the amorphous phase. It is suggested that this broad peak indicates an exothermic reaction due to the structure relaxation depending on the local atomic arrangement transformation in the amorphous phase. Also, the crystallization temperatures of samples by the gas jet flow type electromagnetic levitation process differ slightly from those of the as-cast bulk metallic glass (BMG) and the melt-spun ribbon in the published results. ${ }^{9)}$ One reason is that the method of preparation and the cooling condition of samples by the containerless process differ from those of the as-cast BMG and the melt-spun ribbon in B. C. Wei et al. ${ }^{9)}$ The difference of experimental results may be caused by the difference of the local structure or the interaction of valance band electron in amorphous phase.

\subsection{Magnetic properties}

Figure 5 shows the $\mathrm{M}-\mathrm{H}$ loops of the solidified $\mathrm{Nd}_{60} \mathrm{Fe}_{30-x} \mathrm{Co}_{x} \mathrm{Al}_{10}$ samples, which were measured at room temperature with a maximum applied field of $1.5 \mathrm{~T}$. The coercivity of $\mathrm{Nd}_{60} \mathrm{Fe}_{20} \mathrm{Co}_{10} \mathrm{Al}_{10}$ sample which is a nearly full amorphous alloy in $\mathrm{XRD}$ pattern is $1.6 \mathrm{kOe}$. The coercivity of $\mathrm{Nd}_{60} \mathrm{Fe}_{15} \mathrm{Co}_{15} \mathrm{Al}_{10}$ and $\mathrm{Nd}_{60} \mathrm{Fe}_{10} \mathrm{Co}_{20} \mathrm{Al}_{10}$ samples which consist of partial crystalline and amorphous phases in XRD

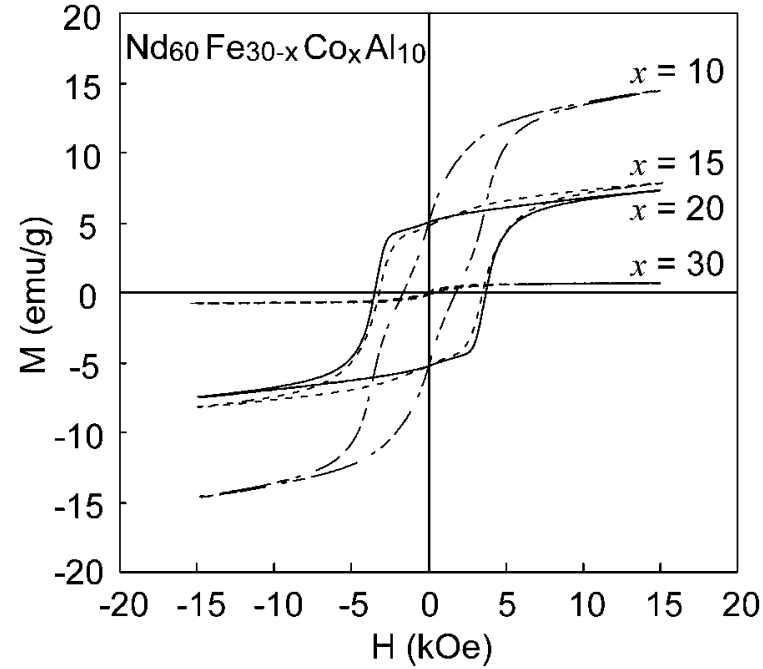

Fig. 5 M-H hysteresis loops of $\mathrm{Nd}_{60} \mathrm{Fe}_{30-x} \mathrm{Co}_{x} \mathrm{Al}_{10}$ samples $(x=10,15$, 20 and 30 ).

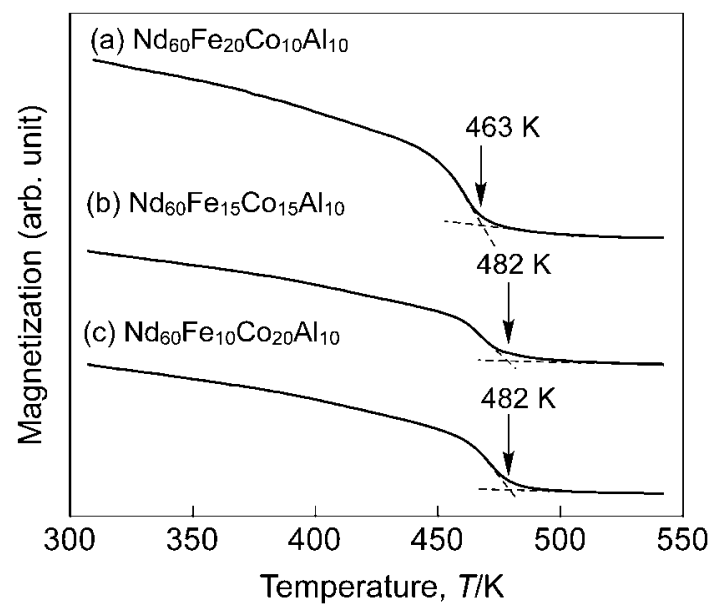

Fig. 6 Temperature dependence of magnetization of $\mathrm{Nd}_{60} \mathrm{Fe}_{30-x} \mathrm{Co}_{x} \mathrm{Al}_{10}$ samples ( $x=10,15$ and 20) measured at a maximum applied field of 500 Oe.

patterns exhibited 3.6 and $3.7 \mathrm{kOe}$, respectively. The substituting Co for Fe is increased the coercivity. Also, as shown in Fig. 6, the Curie temperature exhibits 463, 482 and $482 \mathrm{~K}$ for $\mathrm{Nd}_{60} \mathrm{Fe}_{20} \mathrm{Co}_{10} \mathrm{Al}_{10}, \mathrm{Nd}_{60} \mathrm{Fe}_{15} \mathrm{Co}_{15} \mathrm{Al}_{10}$ and $\mathrm{Nd}_{60} \mathrm{Fe}_{10^{-}}$ $\mathrm{Co}_{20} \mathrm{Al}_{10}$, respectively. Because the amorphous phase is predominant in the structure of $\mathrm{Nd}_{60} \mathrm{Fe}_{20} \mathrm{Co}_{10} \mathrm{Al}_{10}$ sample, the coercivity values of $x=10$ in the M-H loops and the Curie temperature in thermomagnetic curves differ from $x=$ 15 and 20. Especially, the coercivity of $x=15$ and 20 is two times larger than that of $x=10$. Consequently, it is suggested that the exchange coupling between $\mathrm{Nd}$ atom and $\mathrm{Fe}$ atom was enhanced by Co addition. Furthermore, by increasing the substituting $\mathrm{Co}$ for $\mathrm{Fe}$, the random magnetic anisotropy was increased because of the exchange coupling of $\mathrm{Nd}-\mathrm{Co}$. Thereby, in comparison with $x=15,20$, the coercivity of $x=10$ may be lowered. In addition, we have reported about the undercooling solidification behavior and magnetic properties of $\mathrm{Nd}-\mathrm{Fe}-\mathrm{Al}$ ternary alloys, which are solidified in the containerless state. The coercivity of $\mathrm{Nd}_{70} \mathrm{Fe}_{20} \mathrm{Al}_{10}$ was 
$3.4 \mathrm{kOe}^{8)}$ This value is smaller than those of $\mathrm{Nd}_{60} \mathrm{Fe}_{15^{-}}$ $\mathrm{Co}_{15} \mathrm{Al}_{10}$ and $\mathrm{Nd}_{60} \mathrm{Fe}_{10} \mathrm{Co}_{20} \mathrm{Al}_{10}$ samples in this study. Also, the Curie temperature in this study differs from that of the published results. ${ }^{9)}$ As mentioned above, we suggested that the difference of the Curie temperature was caused by the amorphous local structure.

\section{Conclusion}

By the gas jet flow type electromagnetic levitation, which enables to solidify the levitated melt in the containerless state, the bulk amorphous formation, the metastable phase and high coercivity appearance were examined and then we obtained the following results.

(1) In containerless process, $\mathrm{Nd}-\mathrm{Fe}-\mathrm{Co}-\mathrm{Al}$ sample exhibited to form an amorphous phase and the validity of a new gas jet flow type levitation process was clarified.

(2) The $\mathrm{Nd}_{60} \mathrm{Fe}_{20} \mathrm{Co}_{10} \mathrm{Al}_{10}$ sample is a nearly full amorphous structure. Also, the undercooling of samples is $70-160 \mathrm{~K}$ under the cooling rate of around $100 \mathrm{~K} / \mathrm{s}$.

(3) By increasing the substituting $\mathrm{Co}$ for $\mathrm{Fe}$, the amorphous formation ability decreases. From DTA curves, the Curie temperature and $\mathrm{M}-\mathrm{H}$ loops, by increasing Co addition, the coercivity exhibited high value up to $3.6 \mathrm{kOe}$.

\section{Acknowledgements}

This work has been supported by a Grant-in-Aid for Scientific Research (C) (2), No. 15560646 from the Ministry of Education, Culture, Sports, Science and Technology.

\section{REFERENCES}

1) S. Sugiyama, S. Ozawa, I. Jimbo, S. Hirosawa and K. Kuribayash: Journal of Cryst. Growth 275 (2005) e2019-e2024.

2) S. Mukherjee, J. Schroers, Z. Zhou, W. L. Johnson and W.-K. Rhim: Acta Mater. 52 (2004) 3689-3695.

3) K. Nagayama, K. Horiuchi, M. Yamashita, J. Kato, T. Suzuki, K. Kuribayashi, M. Kanamura, K. Shibukawa and R. Okumura: J. Jpn. Soc. Microgravity Appl. 16 (1999) 150-156.

4) K. Nagayama, S. Miyairi and H. Sugawara: J. Japan Inst. Metals 63 (1999) 1363-1364.

5) K. Nagayama, S. Kobayashi, T. Yamamura, T. Suzuki, K. Kuribayashi and H. Miyama: J. Japan Inst. Metals 60 (1996) 412-419.

6) K. Nagayama, M. Yamashita, K. Horiuchi, J. Kato, T. Suzuki, K. Kuribayashi, M. Kanamura, K. Shibukawa and R. Okumura: J. Jpn. Soc. Microgravity Appl. 16 (1999) 300-307.

7) S. Azumo and K. Nagayama: J. Japan Inst. Metals 69 (2005) 399-401.

8) S. Utsuno, K. Oda and K. Nagayama: Space Utiliz Res, 21 (2005) 5-8.

9) B. C. Wei, W. Löser, L, Xia, S. Roth, M. X. Pan, W. H. Wang and J. Eckert: Acta Mater. 50 (2002) 4357-4367. 